\title{
Conserved and reproducible bacterial communities associate with extraradical hyphae of arbuscular mycorrhizal fungi
}

\author{
Bryan D. Emmett $\mathbb{B}^{1,2} \cdot$ Véronique Lévesque-Tremblay ${ }^{1,3} \cdot$ Maria J. Harrison $\mathbb{( D}^{1}$
}

Received: 21 September 2020 / Revised: 21 January 2021 / Accepted: 29 January 2021 / Published online: 1 March 2021

(c) The Author(s) 2021. This article is published with open access

\begin{abstract}
Extraradical hyphae (ERH) of arbuscular mycorrhizal fungi (AMF) extend from plant roots into the soil environment and interact with soil microbial communities. Evidence of positive and negative interactions between AMF and soil bacteria point to functionally important ERH-associated communities. To characterize communities associated with ERH and test controls on their establishment and composition, we utilized an in-growth core system containing a live soil-sand mixture that allowed manual extraction of ERH for 16S rRNA gene amplicon profiling. Across experiments and soils, consistent enrichment of members of the Betaproteobacteriales, Myxococcales, Fibrobacterales, Cytophagales, Chloroflexales, and Cellvibrionales was observed on ERH samples, while variation among samples from different soils was observed primarily at lower taxonomic ranks. The ERH-associated community was conserved between two fungal species assayed, Glomus versiforme and Rhizophagus irregularis, though $R$. irregularis exerted a stronger selection and showed greater enrichment for taxa in the Alphaproteobacteria and Gammaproteobacteria. A distinct community established within 14 days of hyphal access to the soil, while temporal patterns of establishment and turnover varied between taxonomic groups. Identification of a conserved ERH-associated community is consistent with the concept of an AMF microbiome and can aid the characterization of facilitative and antagonistic interactions influencing the plant-fungal symbiosis.
\end{abstract}

\section{Introduction}

Arbuscular mycorrhizal fungi (AMF) evolved a symbiotic relationship with plants over 400 million years ago and associate with $\sim 72 \%$ of all land plants today $[1,2]$. The basis of the symbiosis is nutritional and involves the exchange of plant-derived carbon for nutrients, mainly phosphorus and nitrogen, provided by the fungus [3]. The

Supplementary information The online version contains supplementary material available at https://doi.org/10.1038/s41396021-00920-2.

Bryan D. Emmett be68@cornell.edu

$\triangle$ Maria J. Harrison mjh78@cornell.edu

1 Boyce Thompson Institute, Ithaca, NY, USA

2 Present address: USDA Agricultural Research Service, National Laboratory for Agriculture and the Environment, Ames, IA, USA

3 Present address: Laurentian Forestry Center, Canadian Forest Service, Natural Resources Canada, Quebec City, QC, Canada
AMF intraradical hyphae access carbon from the root and this fuels growth of extraradical hyphae (ERH) in the surrounding soil, which forage for mineral nutrients essential for fungal growth and for delivery to the plant [4-6]. This symbiosis does not occur in isolation; growth of ERH increases carbon flow into the soil and influences its spatial distribution as the ERH permeate soil micropores inaccessible to roots [7-9]. In the process, ERH interact with soil microbes; NanoSIMs imaging and ${ }^{13} \mathrm{C}$ tracing have provided direct evidence that ERH rapidly translocate plant carbon to soil microbes in the process of acquiring mineral nutrients [9-11]. Associations between soil bacteria and ERH are therefore a critical link in the ecology and function of the AM symbiosis in natural and managed ecosystems.

The potential significance of ERH-associated microbial communities can be appreciated in light of insights gained from the genomes of several AMF, which are largely devoid of genes encoding phytases and secreted phosphatases $[12,13]$ as well as genes required for the degradation of lignin and complex carbohydrates found in plant cell walls [12-17]. This lack of enzymatic capabilities predicts a reliance on soil microbial communities for the 
release of essential mineral nutrients from complex organic forms. The influence of mycorrhizal ERH on nutrient cycling and to some extent microbial communities has been evaluated using compartmented mesocosms or ingrowth mesh cores which exclude roots. These studies documented increased rates of decomposition and nitrogen mineralization from soil and organic residue in the hyphosphere, the zone of soil influenced by the ERH $[10,18,19]$. Meanwhile, shifts in bacterial community composition were revealed using phospholipid fatty acid analysis and 16S rRNA microarrays [10, 19]. Phytate is a dominant form of organic phosphorus in many soils [20] and in-growth cores enriched in phytate showed increased phosphatase and phytase activities around the ERH, and enrichment of alkaline phosphatase producing bacteria associated with the ERH [21-23]. The diverse, positive effects of individual bacteria have long been known $[24,25]$, but AMF-associated microbial communities are only just beginning to be described [23, 26, 27] and their functions remain to be determined. Importantly, AMF interactions with soil microbial communities are not limited to facilitative or mutualistic responses as soil biota appear to differentially inhibit AMF colonization and activity across diverse soils, whereas in the same steam pasteurized soils such inhibition was not observed [28, 29].

Efforts to investigate microbial communities associated with the ERH face the immense challenge of sampling the delicate and diffuse hyphae from the soil. Consequently, a range of complementary approaches have been devised. In vitro approaches to assess the attachment of individual strains or even complex communities to the ERH have provided evidence for attachment of a subset of the soil bacterial community [30-32]. Furthermore, differential requirements for living or dead hyphae, or for a particular species of AMF, indicate a level of specificity to these interactions [31]. The complementary approach of profiling communities associated with the ERH has so far focused largely on ERH-colonized soil, which may not reveal taxa intimately associated with ERH. Bridging these approaches, artificial soil systems have been used to culture phosphate solubilizing bacteria that attach to the ERH of plants grown in a turface medium [33] and recently, in-growth cores with soil and glass beads [23] have allowed sampling of the ERH-associated community.

Using a modified soil-sand system and gentle rinsing and decanting, ERH can be sampled from a soil-sand matrix and allow high-resolution profiling of ERH-attached communities in a live soil system. Here, in a series of three mesocosm experiments, we detail the bacterial community closely associated with AMF ERH and ask whether this community varies across soils, changes with time, or is influenced by either fungal species or nutrient status of the soil.

\section{Methods}

\section{Mesocosm design and plant growth conditions}

\section{Fungal inoculum}

Surface-sterilized spores of Glomus versiforme (Accession IT104, https://invam.wvu.edu), maintained on leek (Allium porrum L.), were prepared as in Liu et al. [34] with minor modifications including sonicating twice in $0.1 \%$ Tween-20 for $5 \mathrm{~min}$, surface sterilization by two treatments with $2 \%$ Chloramine-T in $0.1 \%$ Tween-20 solution on a shaker for $15 \mathrm{~min}$ each, followed by 1 -h incubation with $200 \mu \mathrm{g} \mathrm{ml}^{-1}$ streptomycin at $4{ }^{\circ} \mathrm{C}$ and then rinsed $5 \mathrm{x}$ with sterile, deionized $\mathrm{H}_{2} \mathrm{O}$. Spores from Rhizophagus irregularis (DAOM197198) maintained in axenic carrot root organ cultures [35] were harvested by blending the agar spore mix twice for $3-4 \mathrm{~s}$ in $20 \mathrm{ml}$ of $10 \mathrm{mM}$ sodium citrate, $\mathrm{pH} 6.0$ and filtering through a $250 \mu \mathrm{m}$ mesh to trap hyphae and root fragments and a $50 \mu \mathrm{m}$ mesh to collect spores before resuspending in sterile deionized $\mathrm{H}_{2} \mathrm{O}$.

\section{Experiment 1}

A mesocosm experiment was conducted to characterize bacterial communities associated with ERH and test whether these communities differed among background soils. Mesocosms (1.62 1 tree pots, Steuwe \& Sons, Tangent, OR, USA) consisted of a plant compartment filled with a sterilized sand-gravel mixture and a hyphal in-growth core containing a live soil (Fig. S1).

The plant compartment was filled with an autoclaved mixture of play sand, filter sand, and gravel $(2: 2: 1 \mathrm{v} / \mathrm{v} / \mathrm{v})$ [36] with a gently firmed layer of autoclaved play sand $(100 \mathrm{ml})$ at a depth of $8 \mathrm{~cm}$ onto which $1000 \mathrm{G}$. versiforme spores were pipetted. A $3 \times 16 \mathrm{~cm}$ cone placeholder was embedded in the plant compartment to reserve space for the hyphal in-growth core. The mesocosms were planted with ten surface-sterilized seeds of Brachypodium distachyon (L.) P. Beauv. line $\mathrm{Bd} 21$ and maintained in a growth chamber under $12 \mathrm{~h}$ light-dark cycle at $22^{\circ} \mathrm{C}$ night and $24^{\circ}$ $\mathrm{C}$ day. Pots were fertilized $3 \mathrm{x}$ weekly with $50 \mathrm{ml} 1 / 4 \mathrm{x}$ modified Hoagland's solution [37] with $20 \mu \mathrm{m}$ potassium phosphate.

Forty-nine days after planting, the cone placeholder was removed and the hyphal in-growth core inserted. This twostage approach was designed to allow the inoculated fungus to colonize the root system and produce a network of ERH, which, supported nutritionally through their connection to the roots, has the capacity to rapidly proliferate in the ingrowth core thus outcompeting any native AMF inoculum introduced with the soil core. The in-growth core consisted of a $2.5 \times 15 \mathrm{~cm}$ mesh core $(50 \mu \mathrm{m}$, Midwest Filter, St. 
Charles, IL, USA) containing a live (unsterilized) $2 \mathrm{~mm}$ sieved soil mixed with autoclaved play sand $(1: 1 \mathrm{v} / \mathrm{v})$. Three replicate mesocosms were established for each of three field soils from Dryden, New York $\left(42^{\circ} 31^{\prime} 16^{\prime \prime} \mathrm{N}, 76^{\circ} 19^{\prime} 51^{\prime \prime} \mathrm{W}\right)$, Florence, South Carolina $\left(34^{\circ} 18^{\prime} 41^{\prime \prime} \mathrm{N} 79^{\circ} 45^{\prime} 15^{\prime \prime} \mathrm{W}\right)$, or Pendleton, South Carolina $\left(34^{\circ} 37^{\prime} 37^{\prime \prime} \mathrm{N} 82^{\circ} 44^{\prime} 27^{\prime \prime} \mathrm{W}\right)$. These soils are distinct in texture and carbon content (Table S1). Additionally, mesocosms were established with cores filled only with autoclaved play sand to assess the composition of a community established in the absence of a live soil inoculum (see Supplementary Text and Figs. S2 and S3 for results). Following insertion of the core, ERH were allowed to colonize the core for 84 days before the cores were removed and mesocosms harvested (Figs. 1a and $\mathrm{S} 1$ ).

\section{Experiment 2}

A second experiment was conducted to confirm that results from Experiment 1 could be replicated and to test the effect of fungal species and soil nutrient status on the composition of the ERH-associated bacterial community. Soil was collected from independent locations within each of the same fields used in Experiment 1, stored at $4{ }^{\circ} \mathrm{C}$, and handled as separate replicates for the duration of the experiment. Mesocosms and experimental conditions were maintained as in Experiment 1, with the following adjustments. Mesocosms included four in-growth cores, two colonized by hyphae and a third rotated $720^{\circ}$ daily to prevent hyphal access. A fourth core allowed both root and hyphal access but was not sampled in this experiment. The proportion of the soil component of hyphal in-growth cores was reduced to 1:3 live soil: autoclaved sand (w/w) mixture and the core mesh size reduced to $25 \mu \mathrm{m}$. Mesocosms were inoculated with $1000 \mathrm{G}$. versiforme spores. In order to test whether fungal species influenced the ERH community, additional mesocosms slated to receive Dryden soil were inoculated with $3000 R$. irregularis spores. A nutrient treatment of low phosphorous (1/4x modified Hoagland's solution with 20 $\mu \mathrm{m}$ potassium phosphate) or low nitrogen fertilizer regime (1/4x Hoagland's solution with $200 \mu \mathrm{m}$ potassium phosphate and 1/20x nitrogen) was imposed on mesocosms containing Dryden and Florence soils following core insertion. This resulted in 7 treatment combinations and 28 experiment units $(n=4$, Table S2). All treatments received nitrogen as $\mathrm{NH}_{4} \mathrm{NO}_{3}$. Mesocosms were harvested 27 days after core insertion.

\section{Experiment 3}

To characterize the temporal dynamics of community establishment and succession on the hyphae a time course experiment was undertaken using the Dryden soil collected in Experiment 2. Mesocosms of 0.661 deepots (Steuwe \& Sons, Tangent, OR) were inoculated with 300 spores of $G$. versiforme and planted with two seeds of $B$. distachyon. Fewer spores were used as the pot volume was smaller in this experiment. Two cone placeholders were removed 49 days after planting and replaced with $25 \mu \mathrm{m}$ mesh cores filled with a $1: 3(\mathrm{w} / \mathrm{w})$ mixture of live soil and autoclaved play sand. One core was rotated $720^{\circ}$ daily to prevent hyphal access, while hyphae were allowed to access the other core. Pots were fertilized 3x weekly with $25 \mathrm{ml}$ of 1/ 4x modified Hoagland's solution with $20 \mu \mathrm{m}$ potassium phosphate. Six replicate mesocosms were harvested 14, 24, 35,45 , and 65 days after cores were inserted.

\section{Harvest and sample analysis}

The mesh core was removed, cut open vertically with ethanol-rinsed scissors, and the soil-sand mixture placed in a large petri dish. The mixture was gently washed by filling the dish with sterile deionized $\mathrm{H}_{2} \mathrm{O}$ and decanting six times. The hyphal mass was transferred to a fresh petri plate in sterile phosphate-buffered saline (PBS) and hyphae removed from the mass and cleaned of adhering particulate organic matter (POM) using forceps and a 24-gauge needle under a dissecting scope. Hyphae were rinsed by transferring through droplets of sterile PBS in a sterile petri dish and the process repeated until an ERH sample mainly free of POM was collected in a microfuge tube as "core ERH" sample (Fig. 1a, b). In Experiment 1 and later harvests of Experiment 3, some roots had penetrated all hyphal cores. In such cases, hyphae were separated from roots under the dissecting scope and inspected to ensure no root fragments remained as part of the sample.

Additional samples types were collected as controls to identify organisms comparatively enriched on the ERH (Figs. 1a and S1). Following removal of hyphae, a bulb syringe was used to collect a "soil slurry" of the soil-sand matrix under the dissecting scope, providing the primary control for comparison and identification of the ERHassociated community. Additionally, "bulk soil" and "bulk hyphosphere" samples were collected from the rotated core and second intact core, respectively, by homogenizing the soil-sand mixture in a sterile petri plate with an ethanol cleaned spatula and collecting in $2 \mathrm{ml}$ microcentrifuge tubes. Prior to mixing and collection of bulk hyphosphere samples, the cores were inspected to ensure there were no roots present.

It was not possible to completely clear hyphae of all adhering POM (Fig. 1b), therefore, two efforts were made to confirm ERH communities did not reflect POM retained in core ERH samples. First, POM samples were collected from the bulk soil cores following the same process as the core ERH collection-rinsing and decanting with sterile 
(a)

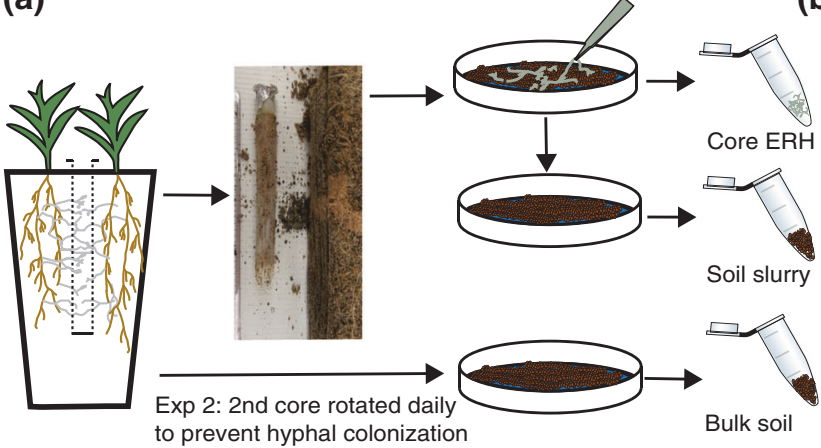

(c)

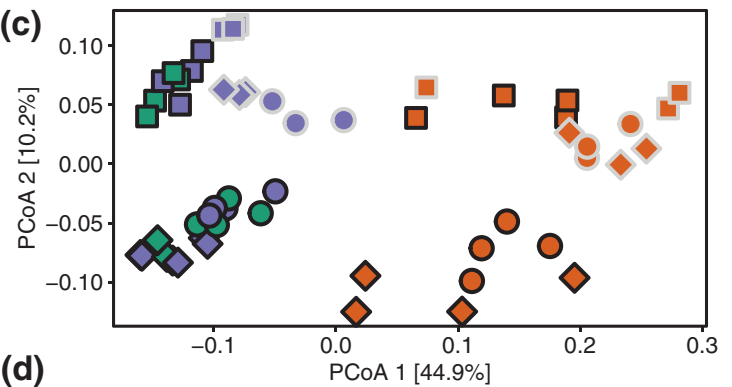

(b)
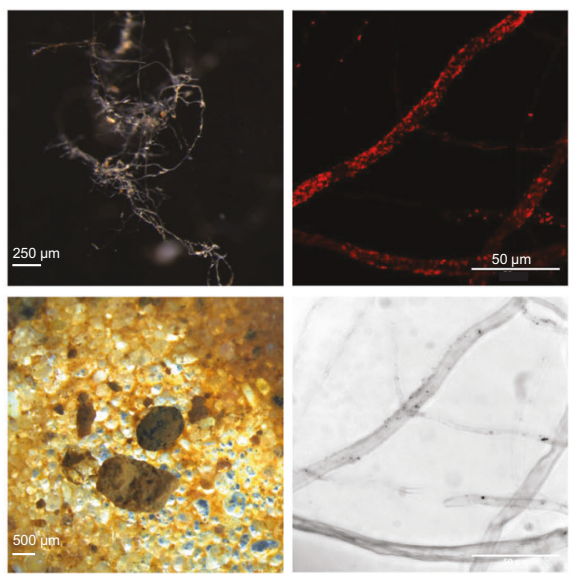

Florence

Dryden

Pendleton

Experiment:

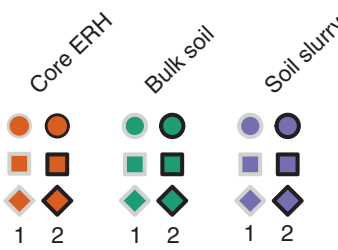

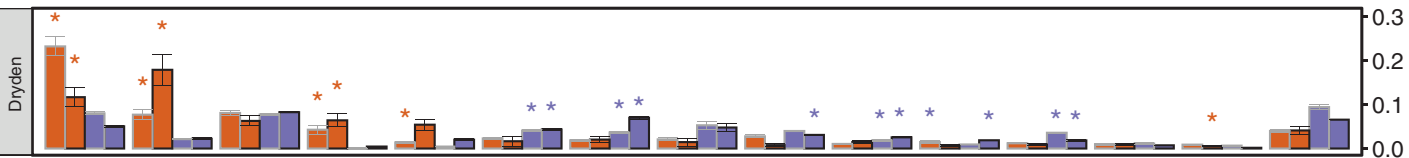
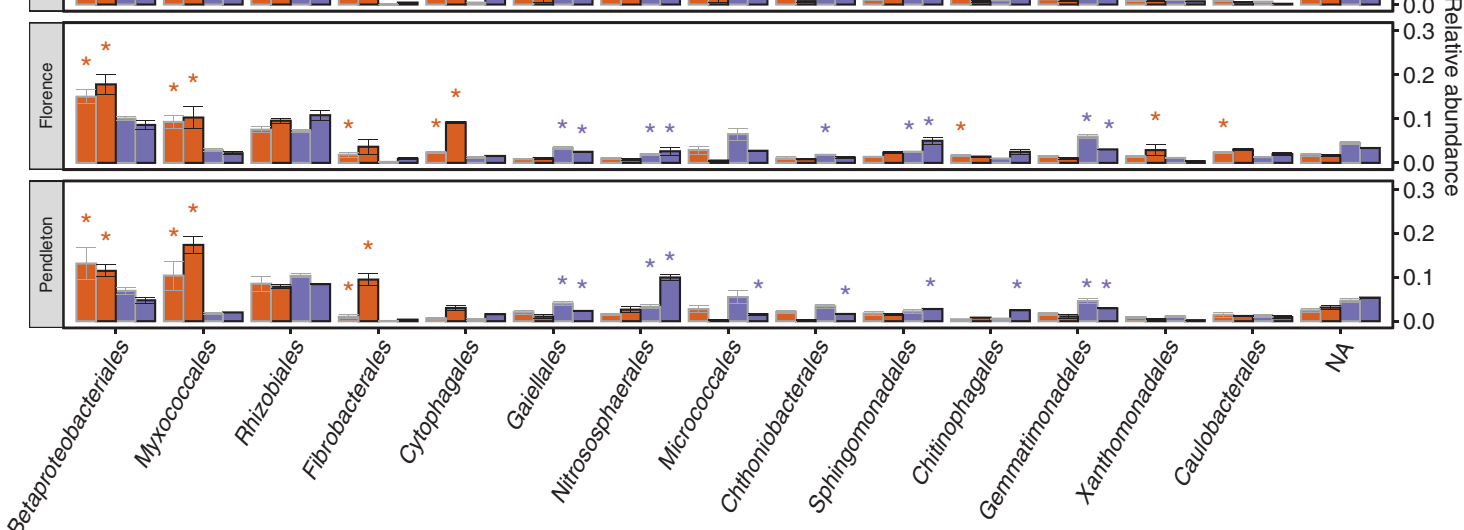

Fig. 1 Distinct bacterial communities associate with the ERH of $G$. versiforme. a Mesocosm design and sample processing. b Clockwise from upper left: Core ERH sample, fluorescent in situ hybridization with universal bacteria probe EUB338-Alexa 594 visualizing bacteria on ERH, brightfield image of ERH, brightfield image of soil slurry sample. c Principal coordinate analysis of weighted-UniFrac distances displays variation among sample types and soils. d Community composition of ERH samples is consistent across soils and

deionized $\mathrm{H}_{2} \mathrm{O}$ six times, then disrupting aggregates with the back of a spatula and collecting remaining POM by decanting the supernatant through a $50 \mu \mathrm{m}$ nylon filter. The sample was then rinsed with sterile deionized $\mathrm{H}_{2} \mathrm{O}$ and collected in a microfuge tube as "bulk POM" (Fig. S1).

Second, ERH in the root compartment were not in direct contact with the soil matrix, and therefore offered an reproducible in multiple experiments. Relative abundance of 15 most abundant bacterial orders in ERH (orange bars) and core slurry samples (purple bars) is arranged by descending abundance in Dryden core ERH samples. Bars represent mean $( \pm \mathrm{SE})$ of $n=3$ (Experiment 1), $n=8$ (Experiment 2, Dryden and Florence), and $n=4$ (Experiment 2, Pendleton) samples. Bars marked with * are significantly different between ERH and soil slurry samples for the soil and experiment combination (Benjamini-Hochberg adjusted $p<0.05$ ).

opportunity to observe the ERH samples in a neutral medium without interference from organic matter. Roots were rinsed in $\mathrm{ddH}_{2} \mathrm{O}$ and floated in sterile PBS for collection of "root ERH" samples. As a control for comparison with root ERH, a subsample of the sand-gravel matrix in the root compartment was collected in Experiment 2, rinsed with $\mathrm{ddH}_{2} \mathrm{O}$, cleared of hyphae under a dissecting scope and a 
"sand slurry" collected in a bulb syringe. All samples were immediately flash frozen in liquid nitrogen for downstream analysis of nucleic acids.

\section{S rRNA gene sequence analysis}

DNA was extracted from samples and dual-barcoded MiSeq libraries of $16 \mathrm{~S}$ rRNA V4 gene amplicons were prepared and sequenced on the Illumina MiSeq platform. Demultiplexed files from each library were processed separately with the "DADA2" pipeline in R [38] to trim, filter, and infer amplicon sequence variants (ASVs) in each sample, remove chimeras, and construct a sequence count table. The count table, phylogenetic tree, taxonomy table, and sample metadata were combined in a "phyloseq" object for further analysis [39]. Details of library preparation, sequence processing, and phylogenetic tree construction are summarized in Table S2 and detailed in Supplementary Text. ASVs unclassified at the phylum level were removed from analysis, which also removed three sequences matching Mollicutes/Mycoplasma-related endobacteria (MRE) of $G$. versiforme from the analysis [13], avoiding skewed relative abundance estimates resulting from their high abundance in the hyphal samples. The final data set contained 18876 ASVs. Sequence counts were checked to ensure similar distribution of reads between treatment groups within an experiment and analysis proceeded using non-rarefied count tables [40]. Raw sequence files and associated metadata were deposited in the NCBI sequence read archive under accession \#PRJNA644936. Final phyloseq objects are available in Supplementary Data File 2.

\section{Statistical analysis}

All statistical analyses were conducted in $\mathrm{R}$ 3.6.0 [41]. Beta-diversity among samples was calculated using weighted-UniFrac distances [42] on bacterial ASVs only and visualized using principal coordinate analysis (PCoA) in the phyloseq package. Treatment and sample type effects on beta-diversity were assessed using permutational multivariate analysis of variance using the ADONIS function in the vegan package [43]. Identification of ERH-associated taxa was conducted through comparison with soil slurry samples. This approach focuses on taxa specific to, or enriched on, the hyphal samples rather than background soil populations observed across sample types. The approach also limits the confounding influence of roots that penetrate the core as the soil slurry samples experience the same experimental conditions as the hyphae. Sample type influence on natural log-transformed relative abundance of the 15 most abundant prokaryotic orders was assessed in linear models with soil, experiment, and sample type as fixed effects and pairwise comparisons of sample types within a soil and experiment assessed in the package "emmeans" using Benjamini-Hochberg adjusted $p$ values [44]. Differential abundance of bacterial and archaea ASVs between sample types was determined using a negative binomial model in the DESeq2 package [45]. Hyphalassociated ASVs were identified as those with $\log _{2}$-fold change $>0$ (adjusted $p<0.05$ ) between core ERH and soil slurry samples in any soil (Supplementary Data File 1). To determine if ERH colonization of the bulk hyphosphere was correlated with the abundance of hyphal ASVs, correlation between MRE relative abundance in the untrimmed data set and relative abundance of groups of hyphal ASVs was tested in a linear model with soil type, replicate, and sample type used as covariates. $\mathrm{R}$ code used for sequence processing, statistical analysis, and figure generation are available at https://github.com/bdemmett/Hyphosphere.

\section{Results}

16S rRNA gene profiling revealed a distinct bacterial community associated with ERH of G. versiforme. Core ERH samples from Experiments 1 and 2 clearly separated from the soil slurry and bulk soil samples in the primary axis of the PCoA of weighted-UniFrac distances (Fig. 1c) and sample type accounted for roughly $40 \%$ of the variation among samples from the three soils (Table $1 ; p<0.001$ ). Across experiments and soils, consistent and taxonomically coherent selection was evident in samples of ERH. Hyphal samples were dominated by Proteobacteria (50\% relative abundance $\pm 11 \% \mathrm{SD}$ ), with lesser amounts of Actinobacteria $(10 \pm 5 \%)$, Chloroflexi $(9 \pm 6 \%)$, Acidobacteria $(7 \pm 2 \%)$, Bacteroidetes $(6 \pm 4 \%)$, and Fibrobacteres $(4 \pm$

Table 1 Variance partitioning of bacterial community beta-diversity in Experiments 1 and 2 as measured by weighted-UniFrac distances among sample types, soils, and experimental runs in permutational multivariate analysis of variance.

\begin{tabular}{lrlllll}
\hline & df & SS & MS & F & $R^{2}$ & \multicolumn{1}{l}{$p$} \\
\hline Soil & 2 & 0.46 & 0.23 & 12.35 & 0.14 & $<0.001$ \\
Sample type $(\mathrm{St})^{\mathrm{a}}$ & 2 & 1.31 & 0.66 & 35.07 & 0.40 & $<0.001$ \\
Experiment & 1 & 0.26 & 0.26 & 13.85 & 0.08 & $<0.001$ \\
Soil $\times$ St & 4 & 0.16 & 0.04 & 2.08 & 0.05 & 0.011 \\
St $\times$ experiment & 1 & 0.09 & 0.09 & 5.07 & 0.03 & 0.002 \\
Soil $\times$ experiment & 2 & 0.27 & 0.13 & 7.12 & 0.08 & $<0.001$ \\
Residuals & 41 & 0.77 & 0.02 & & 0.23 & \\
Total & $53^{\mathrm{b}}$ & 3.32 & & & 1 & \\
\hline
\end{tabular}

Soils: Dryden, Florence, Pendleton.

${ }^{\text {a }}$ Sample types include soil slurry, bulk soil, and core extraradical hyphae.

b Only samples from low phosphorous mesocosms included in PERMANOVA to allow comparison across experiments. 


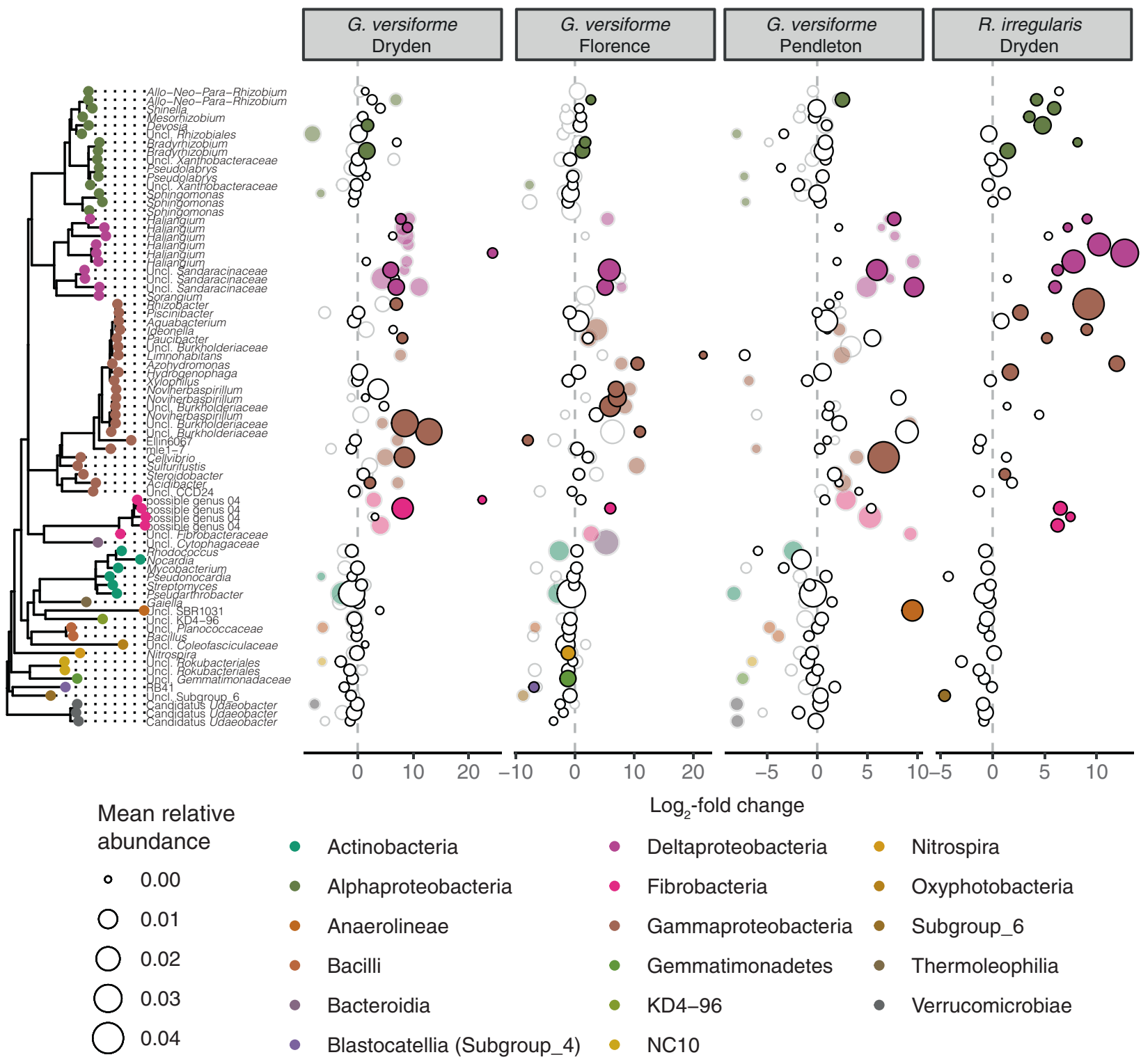

Fig. 2 ERH-associated communities of $G$. versiforme are largely conserved at the family and order levels across three soils and between fungal species. Differential abundance of ASVs between core ERH and soil slurry samples in three soils in Experiment 1 (gray outlines, transparent fill; $n=3$ ) and Experiment 2 (black outlines, solid fill; $n=8$ for Dryden and Florence soils and $n=4$ for Pendleton).

4\%). At the order level, hyphal samples showed a marked increase in relative abundance of Betaproteobacteriales, Myxococcales, Fibrobacterales, and Cytophagales compared to the soil slurry (Fig. 1d). These changes followed the enrichment of 298 ASVs in hyphal samples $(p<0.05)$ (Fig. 2), which were largely within the same orders. Several ASVs within Alphaproteobacteria and Gammaproteobacteria outside of the Betaproteobacteriales were also enriched in ERH samples (Fig. 2), but these groups were less consistently enriched across soils and the overall abundance did not increase in ERH samples (Fig. 1d).
ASVs with significant $\log _{2}$-fold change (DESeq2: adjusted $p<0.05$ ) are colored by taxonomic class. Nonsignificant points have white fill. Taxa organized by phylogenetic tree (left) and $\log _{2}$-fold change between core slurry and hyphal samples indicated by position on $x$-axis. Point size indicates mean relative abundance across soil slurry and core ERH samples. Note R. irregularis included only in Experiment 2.

Background soil influenced community composition in both ERH samples and bulk soil and soil slurry controls, yet the taxonomic selection evident in ERH-associated communities was consistent across soils. Communities from different source soils separated on the second axis of the ordination and accounted for $14 \%$ of the variation in weighted-UniFrac distances (Table $1, p<0.001$ ). Soils separated mainly by biogeography, as the Pendleton, SC and Florence, SC soils, clustered more closely together compared to the Dryden, NY soil. The strength of the soil effect varied between experiments, with greater separation 
between soils in Experiment 2 (Fig. 1). Nevertheless, the reproducibility of the hyphal community was high, with only $5 \%$ of the variation accounted for by the interaction of soil and sample type and only $3 \%$ of variation attributed to the interaction of sample type and experimental run (Table $1, p=0.011$ and $p=0.002$, respectively). The ERHassociated community was largely conserved at the family and order levels across soils with variation expressed at lower taxonomic ranks. Enrichment of individual hyphal ASVs was mostly specific to a particular soil and experimental run (Fig. 2). However, a number of ASVs were enriched in multiple soils from both experiments, including ASVs within the Myxococcales, Sandaracinaceae, and Haliangiaceae families, the Burkholderiaceae and a Cellvibrio ASV (Fig. 2).

Additional controls were included in Experiment 2 to test whether the hyphal extraction technique contributed to experimental artifacts and confirm that the taxonomic shifts observed in hyphal samples were robust (Fig. S4). The bulk soil and soil slurry samples provided controls that were not colonized by ERH or were processed similarly to the hyphal samples and could be used to evaluate hyphal community composition. Both controls clustered closely together, indicating that sample processing was not driving the observed variation in community composition. Additionally, of the 221 ASVs enriched in hyphal samples of G. versiforme, only 34 were also enriched when comparing the POM samples with the same soil slurry. Moreover, a similar taxonomic profile of differentially abundant taxa was established when comparing hyphal samples directly to POM samples (Fig. S5). Thus, most hyphal-associated ASVs were unlikely to be identified due to adhering POM and the majority were not organic matter generalists. Observed generalist ASVs included several Rhizobiales, Chloroflexales, a Cellvibrio, and other phylogenetically diverse taxa.

Samples of ERH collected from the root compartment were evaluated to determine whether the ERH-associated community would establish in a neutral medium. The composition of root ERH was consistent with the family and order level taxonomic selection observed in the hyphae extracted from the soil cores (Fig. S6). Only 41 ASVs were differentially abundant in the root ERH samples (adjusted $p$ $<0.05$ ) compared to the sand slurry, possibly a result of roots and hyphae providing the primary carbon source and driving community composition in this compartment. Similar to the core ERH, differentially abundant ASVs were drawn from the Myxococcales, Fibrobacterales, Cellvibrionales, Chloroflexales, and Betaproteobacterales (Fig. S5).

Comparison of bulk hyphosphere with bulk soil allowed further confirmation that sample processing was not producing experimental artifacts. This comparison was less sensitive than direct extraction of ERH in identifying hyphal-associated taxa. Only a few ASVs were differentially abundant between bulk hyphosphere and bulk soil ( $\log _{2}$-fold change $>0$, adjusted $p<0.05$ ), but included previously identified Burkholderiaceae, Sandaracinaceae, Herpetosiphon (Chloroflexi), and Acidibacter (Gammaproteobacteria) ASVs. However, a priori knowledge of the ERH-associated community could be confirmed in an undisturbed system when controlling for the extent of ERH colonization of the in-growth core using the relative abundance of three sequences from Mollicutes/Mycoplasmarelated endosymbionts of $G$. versiforme [13]. Grouped by order, hyphal ASVs from the Myxococcales and Fibrobacterales were both at higher abundance in hyphosphere soils and positively correlated with MRE relative abundance (Fig. S5). Hyphal ASVs from the Betaproteobacteriales were also more abundant in hyphosphere soils. In contrast, the more generalist Chloroflexales and Rhizobiales were not at higher relative abundance in hyphosphere samples or correlated with MRE abundance (Fig. S7).

\section{Fungal species and fertility treatments}

Comparison of the ERH-associated communities of $R$. irregularis and $G$. versiforme revealed that the ERHassociated community was conserved, with differences observed between species in the strength and specificity of selection. In the Dryden soil, where both $R$. irregularis and G. versiforme hyphal samples were analyzed, fungal species accounted for $5 \%$ of the variation among samples with an additional $8 \%$ of the variation explained by the interaction of fungal species with sample type (Fig. 3 and Table 2; $p<$ $0.001)$. $R$. irregularis appeared to exert stronger selection on the hyphal communities, resulting in 236 ASVs enriched in $R$. irregularis ERH samples compared to 88 ASVs enriched in G. versiforme samples from the same Dryden soil (Fig. 2). The taxonomic profile of the two fungi was similar, but with greater enrichment of Alphaproteobacteria and Gammaproteobacteria in samples of $R$. irregularis.

In contrast to the strength of sample type and fungal species, there was no significant effect of modulating the fertilization regime. Hyphae from mesocosms fertilized with either low phosphorous or low nitrogen modified Hoagland's solutions were not significantly different in weighted-UniFrac distances ( $p=0.308$; Fig. S8).

\section{Temporal patterns}

In a time-series experiment, hyphal in-growth cores were sampled between 14 and 65 days after insertion to identify temporal patterns of establishment or succession in the observed community. A distinct ERH-associated community was established by 14 days and became progressively 
(a)

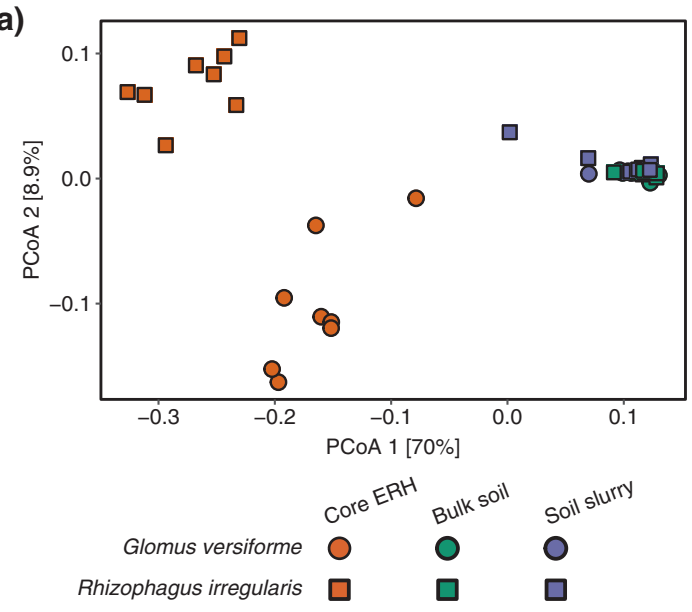

(b)

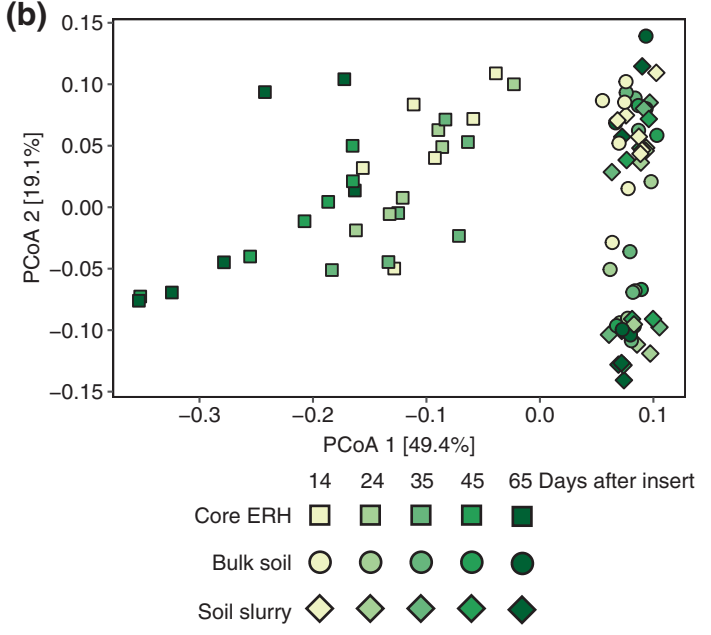

(c)

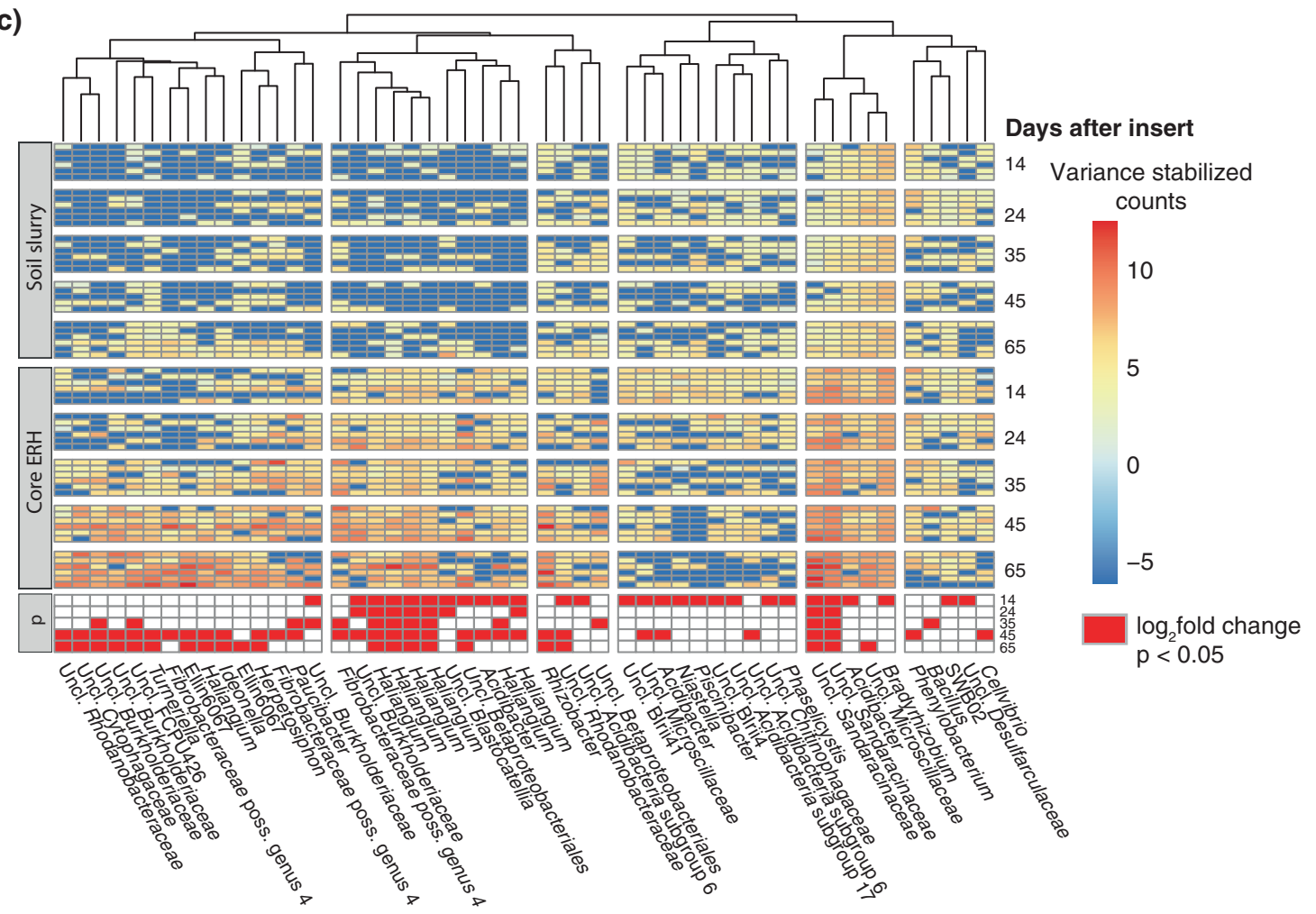

Fig. 3 Fungal species and temporal dynamics influence composition of ERH-associated bacterial communities. Principal coordinate analysis of weighted-UniFrac distances displays variation among sample types and fungal species (a) and over time (b) in Dryden soil. Heatmap of sequence counts, following DESeq2 variance stabilization

transformation, displaying variation in ASV abundance over time (c). Differential abundance tests for each time point shown below. Shown for clarity: 50 most abundant ASVs identified as significantly enriched in core ERH samples during at least one time point.

more distinct from bulk soil and soil slurry samples over time (Fig. 3b) as the portion of reads from hyphal ASVs increased from $17 \pm 2 \%$ at 14 days to $40 \pm 4 \%$ at 65 days after insert. Overall, temporal variation accounted for $8 \%$ of the variance in weighted-UniFrac distances, while the interaction with sample type explained an additional 9\% (Table $3 ; p<0.001$ ). Myxococcales ASVs typified early and consistently enriched hyphal responders. Of 105 ASVs enriched in ERH samples from at least one time point, only $6 \mathrm{ASVs}$ from the
Sandaracinaceae and Haliangiaceae families (order Myxococcales) were significantly enriched at all sampling dates. Other groups established early but decreased in abundance over time, including ASVs from the BIrii41 family, some Acidibacter and Dokdonella (Gammaproteobacteria) (Fig. 3c). Members of the Betaproteobacteriales were also early colonizers of the hyphal samples, but there was turnover in this group as individual ASVs decreased in abundance and others increased in abundance over time. Meanwhile, Cytophagales, 
Table 2 Variance partitioning of bacterial community beta-diversity as measured by weighted-UniFrac distances among sample types and fungal species ( $G$. versiforme and $R$. irregularis) in permutational multivariate analysis of variance.

\begin{tabular}{lrllrlr}
\hline & df & SS & MS & \multicolumn{1}{c}{ F } & \multicolumn{1}{l}{$R^{2}$} & \multicolumn{1}{c}{$p$} \\
\hline Replicate block & 3 & 0.08 & 0.03 & 2.83 & 0.03 & 0.015 \\
Sample type $(\mathrm{St})^{\mathrm{a}}$ & 2 & 1.55 & 0.77 & 82.91 & 0.68 & $<0.001$ \\
Fungus & 1 & 0.1 & 0.1 & 11.11 & 0.05 & 0.002 \\
St $\times$ fungus & 2 & 0.18 & 0.09 & 9.43 & 0.08 & $<0.001$ \\
Residuals & 39 & 0.36 & 0.01 & & 0.16 & \\
Total & 47 & 2.27 & & & 1 & \\
\hline
\end{tabular}

${ }^{a}$ Sample types include soil slurry, bulk soil, and core extraradical hyphae samples. All samples taken from Dryden soil.

Table 3 Variance partitioning of bacterial community beta-diversity among sample types and sampling date in permutational multivariate analysis of variance.

\begin{tabular}{lrlllll}
\hline & df & SS & MS & \multicolumn{1}{c}{ F } & \multicolumn{1}{l}{$R^{2}$} & $p$ \\
\hline Replicate block & 5 & 0.42 & 0.08 & 5.72 & 0.12 & $<0.001$ \\
Sample type $^{\mathrm{a}}$ & 2 & 1.48 & 0.74 & 50.05 & 0.42 & $<0.001$ \\
Days after insert (DAI) $^{\mathrm{b}}$ & 4 & 0.27 & 0.07 & 4.58 & 0.08 & $<0.001$ \\
Sample type $\times$ DAI $_{\text {Residuals }}$ & 8 & 0.31 & 0.04 & 2.61 & 0.09 & $<0.001$ \\
Total & 68 & 1.01 & 0.01 & & 0.29 & \\
\hline
\end{tabular}

a Sample types include soil slurry, bulk soil control, and core extraradical hyphae samples. All samples taken from Dryden soil.

${ }^{\mathrm{b}}$ In-growth cores harvested 14, 24, 35, 45, and 65 days after insert.

Chloroflexales, and Fibrobacterales increased in abundance over time.

\section{Discussion}

In a series of mesocosm experiments, we have detailed a conserved and reproducible bacterial community associated with ERH of two AMF species during symbiosis with $B$. distachyon. Repeated enrichment for members of the Betaproteobacteriales, Myxococcales, Fibrobacterales, Cytophagales, Chloroflexales, and Cellvibrionales was observed in ERH samples across experiments and divergent soils. ASVs from other groups, such as the Alphaproteobacteria and Gammaproteobacteria, were also enriched in hyphal samples, but were more variable across soils and did not achieve higher abundance as a group. Within this taxonomic structure, there was a smaller but notable variation observed at the level of individual ASVs as few ASVs were enriched across all soils. Similar taxonomic selection was observed in both fungal species assayed.

The concept of an AMF-associated microbiome has largely been discussed in relation to endobacteria inhabiting the cytoplasm or membrane-bound compartments of many
AMF species [46-48]. While endobacteria represent the closest association of AMF and bacteria, the results presented here on recurring associations at the ERH surface may also be viewed in the context of an AMF microbiome. In this context, it appears there is a core microbiome associated with the ERH of AMF, shaped by selection at higher taxonomic ranks, but with expressed variation among soils. This dynamic is similar to plant root and rhizosphere microbiomes, where broad selection for particular phylogenetic groups is consistent across sites and expression of unique microbiome composition likely arises in response to site-specific constraints or microbe-microbe interactions [49-51].

The Betaproteobacteriales, formerly the Betaproteobacteria [52], are frequent and significant components of plant microbiomes $[49,53]$ and our results add to previous reports of their interaction with AMF. Betaproteobacteriales interaction with AMF range from the vertically transmitted endosymbionts known as Burkholderia-like organisms (Candidatus Glomeribacter gigasporarum) [17, 47, 48, 54] to more broad fungal-associated lifestyles. In vitro attachment of Betaproteobacteria to ERH was observed by Scheublin et al. [32], who found Oxalobacteraceae were overrepresented in hyphal attached communities. Similarly, Offre et al. [55, 56] found that Oxalobacteraceae were preferentially associated with mycorrhizal roots as compared to non-mycorrhizal roots. In this study, hyphal ASVs from the Betaproteobacteriales were mainly within the Burkholderiaceae and primarily consisted of taxa formerly classified as Comamonadaceae but included some formerly classified as Oxalobacteraceae [52]. The Burkholderiaceae are significant producers of exo- and lipopolysaccharides in soil [57] and bacterial biofilm formation on ectomycorrhizal fungal hyphae appears to be widespread [58]. This capability could be a mechanism of attachment to the ERH surface and also contribute to mycorrhizal impacts on soil aggregation and structure in the field [59, 60]. Additionally, several taxa display antifungal activity, including chitinolytic genera [61, 62]. Turnover of ERH in the field is rapid [63] and chitinolytic organisms associated with ERH may be poised to benefit from the input of fungal biomass.

A striking observation in our data sets is the consistent enrichment of putative bacterial predators in hyphal samples. The Myxococcales, a group known for their predatory and social behavior [64], were universally enriched across soils and strong and consistent colonizers throughout the time course experiment. Several other hyphal ASVs are also known bacterial predators, including Herpetosiphon (Chloroflexales), Cytophagaceae ASVs (Cytophagales), Bdellovibrio (Bdellovibrionales), and a Micavibrionales ASV [65]. The strong increase in abundance of bacterial predators could indicate changing trophic structure in the 
hyphosphere and contribute to the mineralization of nutrients from microbial biomass. From the predator standpoint, if the surface of ERH are enriched in bacterial populations, the hyphae may serve as linear feeding lanes. Alternately, it cannot be ruled out that these organisms are antagonistic to the fungi as several have been noted to prey on fungi or inhibit fungal activity $[66,67]$. Though to our knowledge there is no evidence for myxobacteria grazing on AMF.

Beyond predatory lifestyles, many of the bacterial predators and other ERH-associated taxa are well equipped with hydrolytic enzymes for breaking down complex substrates [68]. Similar to rhizosphere dynamics, such organisms may utilize fungal exudates to subsidize the production of expensive extracellular enzymes. In a recent metagenome resolved transcriptomic study, both Burkholderiaceae and Fibrobacteria upregulated transcription of carbohydrate active enzymes $3 x$ greater in combined rhizosphere and detritosphere habitats than when exposed to either substrate alone [69]. These groups are candidates for further investigation for their contribution to observed hyphosphere priming of carbon and nitrogen mineralization $[19,70,71]$.

\section{Fungal species}

While sharing a broad taxonomic profile, $R$. irregularis and $G$. versiforme differed in the strength and specificity of selection on the hyphal-associated community. Host species selection on microbiome composition is frequently observed in mammalian, plant, and invertebrate systems [72-75]. R. irregularis and G. versiforme diverged $\sim 331 \mathrm{Ma}$ years ago [13] and therefore it is not surprising that variation in traits shaping their associated microbiota would evolve. These findings are consistent with previous reports of variation among AMF lineages in their associated microbiota following long-term co-cultures with the same host plant [76] and observations that bacterial strain ability to attach to and colonize ERH in vitro depended on the fungal species assayed [31]. The traits driving this selection remain unexplored. Fungal exudates have been noted to influence soil bacterial community composition and metabolism of associated bacteria [77, 78]. If AMF species vary in hyphal exudates, metabolites, or signaling that drives changes in the composition and activity of hyphalassociated bacterial communities, such variation could have important implications for nutrient cycling in soil and contribute to functional variation among AM symbioses.

\section{Nutrient status}

In contrast to earlier reports, modulating nutrient availability $[23,79]$ did not alter the composition of the ERHassociated community. This conflict may result from the type of fertilizer and its impacts on the physiochemical environment. Toljander et al. [79] found that fertilizerdriven shifts in the mycorrhizosphere community were largely correlated with $\mathrm{pH}$, a well-known determinant of bacterial community composition [80, 81]. We did not measure $\mathrm{pH}$ in the mesocosms, but regular application of the liquid Hoagland's solution may have limited variation between the treatments. Additionally, inorganic and soluble forms of both nitrogen and phosphorous were used, potentially limiting selection for nutrient specialists.

\section{Temporal trends}

A time course of sampling, 14-65 days after in-growth cores were inserted, allowed us to observe the dynamic establishment of the hyphal attached community. These temporal dynamics were largely consistent with variation between Experiments 1 and 2, when the in-growth cores were in place for 87 and 27 days, respectively. Fewer ASVs from the Betaproteobacteriales were enriched in hyphal samples from Experiment 2, along with a lower abundance of Cytophagales, Fibrobacterales, and Chloroflexales (Figs. 2 and 3). These same groups showed a strong increase in abundance over time in Experiment 3. Similar turnover of rhizosphere bacterial communities has been observed and linked with changes in exudate profiles of the host plant during development $[82,83]$. Whether metabolic changes in the hyphal network manifest over time as the host plant growth slows or whether differences in bacterial growth rates or microbe-microbe interactions, such as the increased abundance of bacterial predators, explain the dynamics we observed is an open question.

\section{Conclusion}

AMF play a critical role in plant nutrient acquisition and are looked to as an important strategy to support ecological intensification of agricultural systems [84]. To fulfill that promise, improved understanding of the ecology of AMF, including their interaction with other soil biota, will be critical. We propose that the hyphal-associated community detailed here reflects a broad adaptation among certain bacterial groups to a fungal-associated lifestyle and suggest that refinement of this community occurs among fungal species and soils as individual strains interact with the fungi and compete in a given environment. Identification of this AMF-associated microbiota can guide future efforts to understand the fungal-bacterial interactions that give rise to this community and identify organisms beneficial or antagonistic to AMF in the field. Broadening this analysis to the genes and functions of the AMF-associated microbiome and interrogation of AMF interactions with other eukaryotic 
soil biota will be necessary to fully appreciate the ecology of these important plant symbionts.

Acknowledgements We thank Daniel Buckley (Cornell University) for use of lab space and equipment for amplicon library preparation and Stephen Kresovich (Clemson University) for access to Pendleton and Florence soils. This research was supported by the Office of Science (BER), US Department of Energy, Grant No. DE-SC0014395.

\section{Compliance with ethical standards}

Conflict of interest The authors declare no competing interests.

Publisher's note Springer Nature remains neutral with regard to jurisdictional claims in published maps and institutional affiliations.

Open Access This article is licensed under a Creative Commons Attribution 4.0 International License, which permits use, sharing, adaptation, distribution and reproduction in any medium or format, as long as you give appropriate credit to the original author(s) and the source, provide a link to the Creative Commons license, and indicate if changes were made. The images or other third party material in this article are included in the article's Creative Commons license, unless indicated otherwise in a credit line to the material. If material is not included in the article's Creative Commons license and your intended use is not permitted by statutory regulation or exceeds the permitted use, you will need to obtain permission directly from the copyright holder. To view a copy of this license, visit http://creativecommons. org/licenses/by/4.0/.

\section{References}

1. Wang B, Qiu Y-L. Phylogenetic distribution and evolution of mycorrhizas in land plants. Mycorrhiza. 2006;16:299-363.

2. Brundrett MC, Tedersoo L. Evolutionary history of mycorrhizal symbioses and global host plant diversity. N Phytol. 2018;220:1108-15.

3. Smith SE. Read D 5 - Mineral nutrition, toxic element accumulation and water relations of arbuscular mycorrhizal plants. Mycorrhizal symbiosis. third ed. London: Academic Press; 2008. p. $145-190$.

4. Pearson JN, Jakobsen I. The relative contribution of hyphae and roots to phosphorus uptake by arbuscular mycorrhizal plants, measured by dual labelling with ${ }^{32} \mathrm{P}$ and ${ }^{33} \mathrm{P}$. N Phytol. 1993;124:489-94.

5. Hodge A, Fitter AH. Substantial nitrogen acquisition by arbuscular mycorrhizal fungi from organic material has implications for N cycling. Proc Natl Acad Sci USA. 2010;107:13754-9.

6. Wang S, Chen A, Xie K, Yang X, Luo Z, Chen J, et al. Functional analysis of the OsNPF4.5 nitrate transporter reveals a conserved mycorrhizal pathway of nitrogen acquisition in plants. Proc Natl Acad Sci USA. 2020;117:16649-59.

7. Johnson D, Leake JR, Ostle $\mathrm{N}$, Ineson $\mathrm{P}$, Read DJ. In situ ${ }^{13} \mathrm{CO} 2$ pulse-labelling of upland grassland demonstrates a rapid pathway of carbon flux from arbuscular mycorrhizal mycelia to the soil. $\mathrm{N}$ Phytol. 2002;153:327-34.

8. Finlay RD. Ecological aspects of mycorrhizal symbiosis: with special emphasis on the functional diversity of interactions involving the extraradical mycelium. J Exp Bot. 2008;59:1115-26.

9. Kaiser C, Kilburn MR, Clode PL, Fuchslueger L, Koranda M, Cliff JB, et al. Exploring the transfer of recent plant photosynthates to soil microbes: mycorrhizal pathway vs direct root exudation. N Phytol. 2015;205:1537-51.
10. Nuccio EE, Hodge A, Pett-Ridge J, Herman DJ, Weber PK, Firestone MK. An arbuscular mycorrhizal fungus significantly modifies the soil bacterial community and nitrogen cycling during litter decomposition. Environ Microbiol. 2013;15:1870-81.

11. Wang F, Shi N, Jiang R, Zhang F, Feng G. In situ stable isotope probing of phosphate-solubilizing bacteria in the hyphosphere. $\mathrm{J}$ Exp Bot. 2016;67:1689-701.

12. Tisserant E, Malbreil M, Kuo A, Kohler A, Symeonidi A, Balestrini R, et al. Genome of an arbuscular mycorrhizal fungus provides insight into the oldest plant symbiosis. Proc Natl Acad Sci USA. 2013;110:20117-22.

13. Sun $X$, Chen W, Ivanov S, MacLean AM, Wight H, Ramaraj T, et al. Genome and evolution of the arbuscular mycorrhizal fungus Diversispora epigaea (formerly Glomus versiforme) and its bacterial endosymbionts. N Phytol. 2019;221:1556-73.

14. Lin K, Limpens E, Zhang Z, Ivanov S, Saunders DGO, Mu D, et al. Single nucleus genome sequencing reveals high similarity among nuclei of an endomycorrhizal fungus. PLoS Genet. 2014;10:e1004078.

15. Kobayashi Y, Maeda T, Yamaguchi K, Kameoka H, Tanaka S, Ezawa T, et al. The genome of Rhizophagus clarus HR1 reveals a common genetic basis for auxotrophy among arbuscular mycorrhizal fungi. BMC Genomics. 2018;19:465.

16. Morin E, Miyauchi S, Clemente HS, Chen ECH, Pelin A, Providencia Ide la . et al. Comparative genomics of Rhizophagus irregularis, $R$. cerebriforme, $R$. diaphanus and Gigaspora rosea highlights specific genetic features in Glomeromycotina. N Phytol. 2019;222:1584-98.

17. Venice F, Ghignone S, Fossalunga AS, di, Amselem J, Novero M, Xianan X, et al. At the nexus of three kingdoms: the genome of the mycorrhizal fungus Gigaspora margarita provides insights into plant, endobacterial and fungal interactions. Environ Microbiol. 2020;22:122-41.

18. Hodge A. Arbuscular mycorrhizal fungi influence decomposition of, but not plant nutrient capture from, glycine patches in soil. $\mathrm{N}$ Phytol. 2001;151:725-34.

19. Herman DJ, Firestone MK, Nuccio E, Hodge A. Interactions between an arbuscular mycorrhizal fungus and a soil microbial community mediating litter decomposition. FEMS Microbiol Ecol. 2012;80:236-47.

20. Schachtman DP, Reid RJ, Ayling SM. Phosphorus uptake by plants: from soil to cell. Plant Physiol. 1998;116:447-53.

21. Tarafdar JC, Marschner H. Phosphatase activity in the rhizosphere and hyphosphere of VA mycorrhizal wheat supplied with inorganic and organic phosphorus. Soil Biol Biochem. 1994;26:387-95.

22. Wang X-X, Hoffland E, Feng G, Kuyper TW. Phosphate uptake from phytate due to hyphae-mediated phytase activity by arbuscular mycorrhizal maize. Front Plant Sci. 2017;8:684.

23. Zhang L, Shi N, Fan J, Wang F, George TS, Feng G. Arbuscular mycorrhizal fungi stimulate organic phosphate mobilization associated with changing bacterial community structure under field conditions. Environ Microbiol. 2018;20:2639-51.

24. Mosse B. The establishment of vesicular-arbuscular mycorrhiza under aseptic conditions. Microbiology. 1962;27:509-20.

25. Frey-Klett P, Garbaye J, Tarkka M. The mycorrhiza helper bacteria revisited. N Phytol. 2007;176:22-36.

26. Agnolucci M, Battini F, Cristani C, Giovannetti M. Diverse bacterial communities are recruited on spores of different arbuscular mycorrhizal fungal isolates. Biol Fertil Soils. 2015;51:379-89.

27. Iffis B, St-Arnaud M, Hijri M. Petroleum hydrocarbon contamination, plant identity and arbuscular mycorrhizal fungal (AMF) community determine assemblages of the AMF sporeassociated microbes. Environ Microbiol. 2016;18:2689-704.

28. Cruz-Paredes C, Svenningsen NB, Nybroe O, Kjøller R, Frøslev TG, Jakobsen I. Suppression of arbuscular mycorrhizal fungal 
activity in a diverse collection of non-cultivated soils. FEMS Microbiol Ecol. 2019;95:fiz020.

29. Svenningsen NB, Watts-Williams SJ, Joner EJ, Battini F, Efthymiou A, Cruz-Paredes C, et al. Suppression of the activity of arbuscular mycorrhizal fungi by the soil microbiota. ISME J. 2018;12:1296-307.

30. Bianciotto V, Minerdi D, Perotto S, Bonfante P. Cellular interactions between arbuscular mycorrhizal fungi and rhizosphere bacteria. Protoplasma. 1996;193:123-31.

31. Toljander JF, Artursson V, Paul LR, Jansson JK, Finlay RD. Attachment of different soil bacteria to arbuscular mycorrhizal fungal extraradical hyphae is determined by hyphal vitality and fungal species. FEMS Microbiol Lett. 2006;254:34-40.

32. Scheublin TR, Sanders IR, Keel C, Van Der Meer JR. Characterisation of microbial communities colonising the hyphal surfaces of arbuscular mycorrhizal fungi. ISME J. 2010;4:752.

33. Taktek S, Trépanier M, Servin PM, St-Arnaud M, Piché Y, Fortin J-A, et al. Trapping of phosphate solubilizing bacteria on hyphae of the arbuscular mycorrhizal fungus Rhizophagus irregularis DAOM 197198. Soil Biol Biochem. 2015;90:1-9.

34. Liu J, Blaylock LA, Harrison MJ. cDNA arrays as a tool to identify mycorrhiza-regulated genes: identification of mycorrhizainduced genes that encode or generate signaling molecules implicated in the control of root growth. Can J Bot. 2004;82:1177-85.

35. St-Arnaud M, Hamel C, Vimard B, Caron M, Fortin JA. Enhanced hyphal growth and spore production of the arbuscular mycorrhizal fungus Glomus intraradices in an in vitro system in the absence of host roots. Mycol Res. 1996;100:328-32.

36. Floss DS, Gomez SK, Park H-J, MacLean AM, Müller LM, Bhattarai KK, et al. A transcriptional program for arbuscule degeneration during AM symbiosis is regulated by MYB1. Curr Biol. 2017;27:1206-12.

37. Arnon DI, Hoagland DR. Crop production in artificial culture solutions and in soils with special reference to factors influencing yields and absorption of inorganic nutrients. Soil Sci. 1940;50:463-85.

38. Callahan BJ, McMurdie PJ, Rosen MJ, Han AW, Johnson AJA, Holmes SP. DADA2: High-resolution sample inference from Illumina amplicon data. Nat Methods. 2016;13:581-3.

39. McMurdie PJ, Holmes S. phyloseq: an R package for reproducible interactive analysis and graphics of microbiome census data. PLoS ONE. 2013;8:e61217.

40. McMurdie PJ, Holmes S. Waste not, want not: why rarefying microbiome data is inadmissible. PLoS Comput Biol. 2014;10: e1003531.

41. R Core Team. R: a language and environment for statistical computing. Vienna: R Foundation for Statistical Computing; 2019.

42. Lozupone C, Lladser ME, Knights D, Stombaugh J, Knight R. UniFrac: an effective distance metric for microbial community comparison. ISME J. 2011;5:169-72.

43. Oksanen J, Blanchet FG, Friendly M, Kindt R, Legendre P, McGlinn D, et al.vegan: Community Ecology Package. R package version 2.5-5. 2019. https://CRAN.R-project.org/package=vegan.

44. Lenth R. emmeans: Estimated Marginal Means, aka LeastSquares Means. R package version 1.5.0. 2020. https://CRAN.Rproject.org/package $=$ emmeans.

45. Love MI, Huber W, Anders S. Moderated estimation of fold change and dispersion for RNA-seq data with DESeq2. Genome Biol. 2014;15:550.

46. Desirò A, Salvioli A, Ngonkeu EL, Mondo SJ, Epis S, Faccio A, et al. Detection of a novel intracellular microbiome hosted in arbuscular mycorrhizal fungi. ISME J. 2014;8:257-70.

47. Lastovetsky OA, Ahn E, Mondo SJ, Toomer KH, Zhang A, Johnson LM, et al. Distribution and population structure of endobacteria in arbuscular mycorrhizal fungi at North Atlantic dunes. ISME J. 2018;12:3001.

48. Bonfante P, Desirò A. Who lives in a fungus? The diversity, origins and functions of fungal endobacteria living in Mucoromycota. ISME J. 2017;11:1727-35.

49. Lundberg DS, Lebeis SL, Paredes SH, Yourstone S, Gehring J, Malfatti S, et al. Defining the core Arabidopsis thaliana root microbiome. Nature. 2012;488:86-90.

50. Peiffer JA, Spor A, Koren O, Jin Z, Tringe SG, Dangl JL, et al. Diversity and heritability of the maize rhizosphere microbiome under field conditions. Proc Natl Acad Sci USA. 2013;110:6548-53.

51. Bulgarelli D, Garrido-Oter R, Münch PC, Weiman A, Dröge J, Pan $\mathrm{Y}$, et al. Structure and function of the bacterial root microbiota in wild and domesticated barley. Cell Host Microbe. 2015;17:392-403.

52. Parks DH, Chuvochina M, Waite DW, Rinke C, Skarshewski A, Chaumeil P-A, et al. A standardized bacterial taxonomy based on genome phylogeny substantially revises the tree of life. Nat Biotechnol. 2018;36:996-1004.

53. Ofek M, Voronov-Goldman M, Hadar Y, Minz D. Host signature effect on plant root-associated microbiomes revealed through analyses of resident vs. active communities. Environ Microbiol. 2014;16:2157-67.

54. Bianciotto V, Lumini E, Bonfante P, Vandamme P. 'Candidatus Glomeribacter gigasporarum' gen. nov., sp. nov., an endosymbiont of arbuscular mycorrhizal fungi. Int $\mathrm{J}$ Syst Evol Microbiol. 2003;53:121-4.

55. Offre P, Pivato B, Siblot S, Gamalero E, Corberand T, Lemanceau $\mathrm{P}$, et al. Identification of bacterial groups preferentially associated with mycorrhizal roots of Medicago truncatula. Appl Environ Microbiol. 2007;73:913-21.

56. Offre P, Pivato B, Mazurier S, Siblot S, Berta G, Lemanceau P, et al. Microdiversity of Burkholderiales associated with mycorrhizal and nonmycorrhizal roots of Medicago truncatula. FEMS Microbiol Ecol. 2008;65:180-92.

57. Cania B, Vestergaard G, Kublik S, Köhne JM, Fischer T, Albert A, et al. Biological soil crusts from different soil substrates harbor distinct bacterial groups with the potential to produce exopolysaccharides and lipopolysaccharides. Micro Ecol. 2020;79:326-41.

58. Miquel Guennoc C, Rose C, Labbé J, Deveau A. Bacterial biofilm formation on the hyphae of ectomycorrhizal fungi: a widespread ability under controls? FEMS Microbiol Ecol. 2018;94:fiy093.

59. Rillig MC, Mummey DL. Mycorrhizas and soil structure. N Phytol. 2006;171:41-53.

60. Wilson GWT, Rice CW, Rillig MC, Springer A, Hartnett DC. Soil aggregation and carbon sequestration are tightly correlated with the abundance of arbuscular mycorrhizal fungi: results from longterm field experiments. Ecol Lett. 2009;12:452-61.

61. De Boer W, Gunnewiek PJAK, Kowalchuk GA, Veen JAV. Growth of chitinolytic dune soil $\beta$-subclass Proteobacteria in response to invading fungal hyphae. Appl Env Microbiol. 2001;67:3358-62.

62. De Boer W, Leveau JHJ, Kowalchuk GA, Gunnewiek PJAK, Abeln ECA, Figge MJ, et al. Collimonas fungivorans gen. nov., sp. nov., a chitinolytic soil bacterium with the ability to grow on living fungal hyphae. Int J Syst Evol Microbiol. 2004;54:857-64.

63. Staddon PL, Ramsey CB, Ostle N, Ineson P, Fitter AH. Rapid turnover of hyphae of mycorrhizal fungi determined by AMS microanalysis of ${ }^{14} \mathrm{C}$. Science. 2003;300:1138-40.

64. Shimkets LJ, Dworkin M, Reichenbach H. The myxobacteria. The prokaryotes. New York, NY: Springer; 2006. p. 31-115.

65. Perez-Piqueres A, Edel-Hermann W, Alabouvette C, Steinberg C. Response of soil microbial communities to compost amendments. Soil Biol Biochem. 2006;38:460-70.

66. Bull CT, Shetty KG, Subbarao KV. Interactions between myxobacteria, plant pathogenic fungi, and biocontrol agents. Plant Dis. 2002;86:889-96. 
67. Li Z, Ye X, Liu M, Xia C, Zhang L, Luo X, et al. A novel outer membrane $\beta-1,6$-glucanase is deployed in the predation of fungi by myxobacteria. ISME J. 2019;13:2223-35.

68. Pérez J, Moraleda-Muñoz A, Marcos-Torres FJ, Muñoz-Dorado J. Bacterial predation: 75 years and counting! Environ Microbiol. 2016;18:766-79.

69. Nuccio EE, Starr E, Karaoz U, Brodie EL, Zhou J, Tringe SG, et al. Niche differentiation is spatially and temporally regulated in the rhizosphere. ISME J. 2020;14:999-1014.

70. Paterson E, Sim A, Davidson J, Daniell TJ. Arbuscular mycorrhizal hyphae promote priming of native soil organic matter mineralisation. Plant Soil. 2016;408:243-54.

71. Hestrin R, Hammer EC, Mueller CW, Lehmann J. Synergies between mycorrhizal fungi and soil microbial communities increase plant nitrogen acquisition. Commun Biol. 2019;2:1-9.

72. Ley RE, Hamady M, Lozupone C, Turnbaugh P, Ramey RR, Bircher JS, et al. Evolution of mammals and their gut microbes. Science. 2008;320:1647-51.

73. Brucker RM, Bordenstein SR. The roles of host evolutionary relationships (genus: Nasonia) and development in structuring microbial communities. Evolution. 2012;66:349-62.

74. Schlaeppi K, Dombrowski N, Oter RG, Themaat EVL, van, Schulze-Lefert P. Quantitative divergence of the bacterial root microbiota in Arabidopsis thaliana relatives. Proc Natl Acad Sci USA. 2014;111:585-92.

75. Emmett BD, Youngblut ND, Buckley DH, Drinkwater LE. Plant phylogeny and life history shape rhizosphere bacterial microbiome of summer annuals in an agricultural field. Front Microbiol. 2017;8:2414.

76. Rillig MC, Mummey DL, Ramsey PW, Klironomos JN, Gannon JE. Phylogeny of arbuscular mycorrhizal fungi predicts community composition of symbiosis-associated bacteria. FEMS Microbiol Ecol. 2006;57:389-95.

77. Toljander JF, Lindahl BD, Paul LR, Elfstrand M, Finlay RD. Influence of arbuscular mycorrhizal mycelial exudates on soil bacterial growth and community structure. FEMS Microbiol Ecol. 2007;61:295-304.

78. Zhang L, Feng G, Declerck S. Signal beyond nutrient, fructose, exuded by an arbuscular mycorrhizal fungus triggers phytate mineralization by a phosphate solubilizing bacterium. ISME J. 2018;12:2339.

79. Toljander JF, Santos-González JC, Tehler A, Finlay RD. Community analysis of arbuscular mycorrhizal fungi and bacteria in the maize mycorrhizosphere in a long-term fertilization trial. FEMS Microbiol Ecol. 2008;65:323-38.

80. Lauber CL, Hamady M, Knight R, Fierer N. Pyrosequencingbased assessment of soil $\mathrm{pH}$ as a predictor of soil bacterial community structure at the continental Scale. Appl Environ Microbiol. 2009;75:5111-20.

81. Rousk J, Bååth E, Brookes PC, Lauber CL, Lozupone C, Caporaso JG, et al. Soil bacterial and fungal communities across a pH gradient in an arable soil. ISME J. 2010;4:1340-51.

82. Shi S, Nuccio E, Herman DJ, Rijkers R, Estera K, Li J, et al. Successional trajectories of rhizosphere bacterial communities over consecutive seasons. mBio. 2015;6:e00746-15.

83. Zhalnina K, Louie KB, Hao Z, Mansoori N, Rocha UN, da, Shi S, et al. Dynamic root exudate chemistry and microbial substrate preferences drive patterns in rhizosphere microbial community assembly. Nat Microbiol. 2018;3:470-80.

84. Rillig MC, Aguilar-Trigueros CA, Camenzind T, Cavagnaro TR, Degrune F, Hohmann P, et al. Why farmers should manage the arbuscular mycorrhizal symbiosis. N Phytol. 2019;222:1171-5. 